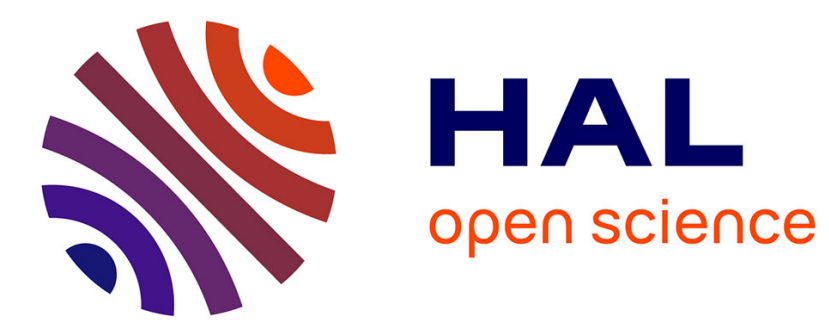

\title{
Physical behavior of highly deformable products during convective drying assessed by a new experimental device
}

Giana Almeida Perré, Julia Parlatore Lancha, Floran Pierre, Joel Casalinho, Patrick Perré

\section{- To cite this version:}

Giana Almeida Perré, Julia Parlatore Lancha, Floran Pierre, Joel Casalinho, Patrick Perré. Physical behavior of highly deformable products during convective drying assessed by a new experimental device. Drying Technology, 2017, 35 (8), pp.906-917. 10.1080/07373937.2016.1233883 . hal-01567126

\section{HAL Id: hal-01567126 \\ https://hal.science/hal-01567126}

Submitted on 22 Nov 2021

HAL is a multi-disciplinary open access archive for the deposit and dissemination of scientific research documents, whether they are published or not. The documents may come from teaching and research institutions in France or abroad, or from public or private research centers.
L'archive ouverte pluridisciplinaire HAL, est destinée au dépôt et à la diffusion de documents scientifiques de niveau recherche, publiés ou non, émanant des établissements d'enseignement et de recherche français ou étrangers, des laboratoires publics ou privés. 


\title{
Physical behavior of highly deformable products during convective drying assessed by a new experimental device
}

\author{
Giana Almeida ${ }^{1}$, Julia Parlatore Lancha ${ }^{1}$, Floran Pierre ${ }^{2}$, Joel Casalinho ${ }^{2}$ and \\ Patrick Perré ${ }^{2}$ \\ ${ }^{1}$ UMR GENIAL, AgroParisTech, Inra, Université Paris-Saclay, 91300 Massy, France \\ ${ }^{2}$ LGPM, CentraleSupelec, Université Paris-Saclay, Grande Voie des Vignes,
} Châtenay-Malabry, France.

\begin{abstract}
This paper presents an experimental device specially designed for the continuous measurement of mass and dimensions of samples submitted to convective drying. This experimental device consists of a magnetic suspension balance and an image acquisition system. The sample deformation is determined by image correlation using a custom software. The entire system is able to achieve accurate mass and dimension measurements over a wide range of temperature and relative humidity. In order to present the potential of this equipment, experimental data of highly deformable food products (potato and apple) submitted to several drying conditions are presented. The obtained results confirm that it is required to consider the actual sample surface to
\end{abstract}


determine the mass flux. This allowed a first drying stage to be observed for potato. Clear differences in physical behavior of these two vegetable products were also observed, for example, an isotropic shrinkage behavior for potato and an anisotropic behavior for apple. These results were explained by the anatomical structure of the products.

Key words : apple; image acquisition; image correlation; highly deformable matters; magnetic suspension balance; parenchyma cells; potato.

\section{INTRODUCTION}

Convective drying at low temperature is a process commonly used in the industry, especially for products that are prone to thermal degradation such as food products. Some advantage of convective drying, compared to other types of drying, are the low price of facilities, easy and cheap process control, flexibility...Nevertheless, even if convective drying is performed at low temperatures, the water removal produces samples shrinkage, generating quality issues, for the product itself but also for the process control, when drying highly deformable products, such as fruits and vegetable. For these reasons, several works studied structural changes of food products caused by convective drying [1-5]. Even if the deformation of highly deformable products during drying has been extensively studied, only few works presented continuous 
measurement of mass and dimension data during drying [6-8]. Acoustic levitation are also among alternative methods of measuring drying kinetics with observation of the sample size [9-10], but, contrary to the device proposed here, those methods are only suitable to study the drying of a liquid droplet.

A full modeling of the coupling between heat/mass transfer and mechanics, including in large deformation, was proposed some time ago [11]. Nowadays, the potential of computational simulation was dramatically extended thanks to the increasing performance of applied mathematics, computational software and power of computer. For example, a mixture of different computational methods was published recently to account for non-linear mechanical drying behavior producing casehardening [12]. Using the possibilities offered by Computational Fluid Mechanics software, it is even possible to imagine the modeling of a whole bed of fixed or fluidized particles, including the airflow around particles and the consideration of the changes of bed morphology due to shrinkage [13].

In addition to a better knowledge gained on the behavior of deformable materials during drying, comprehensive descriptions of the shape evolution versus time is therefore needed to feed these simulation tools or to validate these tools, for example by performing experiment with contrasted drying conditions. For these reasons, our team built a new experimental device capable to accurately made continuous measurement of mass and shape of samples during convective drying. Compared to the 
works published earlier [6, 14], this new device has two crucial advantages: i) it collects the whole shape of the sample shade, not only two orthogonal dimensions at fixed positions and ii) because the new device is build around a magnetic suspension balance, the range of drying conditions is significantly extended. This paper presents the technical aspects of this device, the scientific basis used in data analysis and experimental results gained on two highly deformable food products (potato and apple).

\section{EXPERIMENTAL SETUP}

\section{Magnetic Suspension Balance}

The heart of this device is the magnetic suspension balance (Rubotherm), which allows the sample weight to be transferred to the balance through the chamber wall. As the balance and the electromagnet are completely disconnected from the measuring cell, high values of temperature and relative humidity can be tested without disturbance of the mass measurement. Thus, the balance and the upper part of the electromagnet are in the ambient environment. It is coupled to a permanent magnet placed inside the measuring chamber, which is therefore at the experimental temperature. The sample is attached to a hook, which is suspended thanks to the permanent magnet. A detailed description of this device can be found elsewhere $[15,16]$.

High-resolution magnetic suspension balances allow the changes in force and mass, 
acting on samples placed in controlled environments (pressure, temperature, relative humidity) to be measured with high accuracy. The maximum load of our balance is 80 $\mathrm{g}$, the resolution $0.01 \mathrm{mg}$, the reproducibility $\pm 0.02 \mathrm{mg}$ (standard deviation) and the uncertainty is less than $0.002 \%$ [15].

\section{Temperature and relative humidity control}

The temperature at which tests occur is controlled by a chiller (Ministat230 cc3, HUBER), which circulates water in a double-walled jacket enclosing the measurement chamber. The measuring chamber has a cylindrical shape $(34 \mathrm{~mm}$ diameter and 220 $\mathrm{mm}$ high) and the double-walled jacket (100/160 mm diameter, $425 \mathrm{~mm}$ high) for temperature control were designed and made of stainless steel for this purpose.

The water temperature is controlled with precision of $\pm 0.01{ }^{\circ} \mathrm{C}$. The stability of the air conditions was tested over several days and monitored using a Pt1000 temperature sensor. The variation of the air temperature, peak to peak, is equal to $\pm 0.05{ }^{\circ} \mathrm{C}$. This device is able to control the temperature level in the range 10 to $70{ }^{\circ} \mathrm{C}$.

Concerning the relative humidity control, our device uses a humidity generator (MHG-32, ProUmid GmbH \& Co). This system is able to work with several gases (air, nitrogen, argon, helium, carbon dioxyde) with inlet pressure from 1 to 6 bar and air flow rate from 0 to $500 \mathrm{ml} / \mathrm{min}$. This system controls the desired conditions at the outlet placed right at the chamber entrance, avoiding any change of relative humidity due to condensation along the pathway. The relative humidity (RH) ranges from 2 to 
$98 \%$ (accuracy of $\pm 0.6 \% \mathrm{RH}$ at $23 \pm 5^{\circ} \mathrm{C}$ ). In our experiments, the sets used are: air, inlet pressure of 4 bar and an air flow of $200 \mathrm{ml} / \mathrm{min}$.

\section{Digital Imaging System}

Another key feature of this custom device is the image acquisition system. It consists of a backwards telecentric lightening (TECHSPEC 62-760 Telecentric Backlight Illuminator, Edmund Optics Inc., Barrington, NJ) and a CCD camera (Basler pilot, Model: piA1600-35gm) with a telecentric lens (VICOTAR T151/0.44, Vision \& Control $\mathrm{GmbH})$. The double telecentric system was used to ensure that the image formation is dominated by light paths parallel to the optical axis (acceptance angle $<0.1^{\circ}$ ). The telecentric specifications for the lens system are (i) a working distance of $200 \pm 4 \mathrm{~mm}$, (ii) a maximum object field diagonal of $36.8 \mathrm{~mm}$, (iii) a maximum lateral magnification of 2.30 and (iv) a depth of field of $3.8 \mathrm{~mm}$.

The double-walled jacket presents two holes of $45 \mathrm{~mm}$ diameter and the measurement cell presents two circular windows of $15 \mathrm{~mm}$ (camera side) and $23 \mathrm{~mm}$ (light side) diameter equipped with anti-reflection-coated glass, which permits observation of sample during the test without thermal disturbances (Figure 1).

\section{System Control and Data/Image Acquisition}

All elements of the experimental device are controlled by a PC using a custom software developed in Visual Basic 2012. The desired conditions inside the measurement chamber, respectively relative humidity and temperature, are transmitted 
to the moist air generator (RS232 - Modbus Protocol) and to the chiller (RS232). The sample mass readings are obtained directly from the magnetic suspension balance (RS232) and in order to avoid balance drift, the position of the magnetic coupling is controlled via the parallel port, to tare the balance at regular time intervals. This is an invaluable advantage of this system, because over very long periods of time, the drift of a laboratory balance can be as high of 100 times its resolution. For image acquisition, the software grabs images of sample, at desired intervals of time, via an Ethernet connection. It also proposes options to choose the file format of the image (namely bitmap to keep accuracy or jpeg to save disk space) and its resolution. The room and chamber temperature and relative humidity are also saved at each time increment using a Sensirion kit EKH4 (USB) with two SHT75 sensors (measuring range from 0 to $100 \% \mathrm{RH}$, accuracy $\pm 1.8 \% \mathrm{RH}$ at $25^{\circ} \mathrm{C}$ and from -40 to $123.8{ }^{\circ} \mathrm{C}$, accuracy $\pm 0.3^{\circ} \mathrm{C}$ at $25^{\circ} \mathrm{C}$ ).

The global configuration of the whole experimental setup is presented in Figure 1b.

\section{Strain field by image correlation}

In the present work, the resolution of the raw projection images was $1600 \times 1200$ pixels.

The series of images taken during the experiment were subsequently analyzed to determine the strain tensor by image correlation. The method is based on a global comparison of each deformed image with the initial image (first image taken when drying starts). Considering two points $A$ and $B$ of the objet, the new position $B^{\prime}$ of point 
$B$ after displacement and deformation, is defined with respect to the displacement of point $A$ [17]:

$$
\overrightarrow{A B^{\prime}}=\overrightarrow{A A^{\prime}}+\overrightarrow{A^{\prime} B^{\prime}}
$$

with

$$
\overrightarrow{A^{\prime} B^{\prime}}=(\bar{R} \cdot \overline{\bar{S}}) \overrightarrow{A B}
$$

$\overrightarrow{A A}^{\prime}$ is the translation vector of point $A, \overline{\bar{R}}$ is the rotation tensor and $\overline{\bar{S}}$ is the strain tensor, respectively anti-symmetric and symmetric. In two dimensions, these tensors have simple expressions:

$$
\overline{\bar{R}}=\left(\begin{array}{cc}
\cos & \sin \\
\sin & \cos
\end{array}\right) ; \quad \overline{\bar{S}}=\left(\begin{array}{cc}
s_{x x} & s_{x y} \\
s_{x y} & s_{y y}
\end{array}\right)
$$

By assuming the rotation and the strain field to be uniform over the entire sample, which means that only the global deformation could be determined, the translation vector and the two tensors are constant and equations (1) and (2) apply even when $B$ is not in the vicinity of $A$. A unique point $A$ can therefore be chosen as reference point for the entire image. The new position $B^{\prime}$ of any point $B$ of the image can be computed using equations (1) and (2) as a function of six independent parameters: two for the translation of $A$, one for the angle of rotation and three for the deformation tensor. In practice, the coordinates of point $B,(i, j)$, are integers, but the computed coordinates of $B^{\prime}\left(i^{\prime}, j^{\prime}\right)$ are not. The grey level of point $B^{\prime}$ is therefore compared to the grey level of the real deformed image by a bilinear interpolation of the grey level of the four pixels 
surrounding the position $\left(i^{\prime}, j^{\prime}\right)$. The objective function $F$ is finally defined as:

$$
F=\sqrt{\frac{i, j}{N}\left(g_{i^{\prime}, j^{\prime}}^{\text {cal }} \quad g_{i^{\prime}, j^{\prime}}^{\exp }\right)^{2}}
$$

In order to limit this criterion to the sample, the summation over $i$ and $j$ is limited to the ROI (Region Of Interest) selected manually around the sample on the initial image. This region is defined as a closed chain of points. The whole procedure was implemented in our custom image processing software MeshPore [18]. The Nelder-Mead method is used to find the minimum of the objective function. The software treats automatically the series of hundred of images collected during each test. In order to save CPU time, the initial set of estimated parameters for image $n$ is the identified solution of image $n-1$, which are usually close to the solution of image $n$.

Among the six identified parameters, the translation and rotation are just needed to correct for the small movements of the sample support and the off-diagonal term of the deformation tensor, which is supposed to remain very small, serves as a test to check whether or not the sample shape remains symmetrical. The two diagonal terms of the deformation tensor are the relevant information as they allow the variations of diameter $\mathrm{d}$ (x-axis) and height $\mathrm{h}$ (y-axis) to be computed as a function of initial values $d_{0}$ and $h_{0}$ :

$$
d=s_{x x} d_{0} ; \quad h=s_{y y} h_{0}
$$




\section{EXPERIMENTAL DATA}

\section{Sample preparation}

Products used in this study (apple : Malus domestica Borkh. cv Golden Delicious and potato : Solanum tuberosum L. cv Agata) were bought in a retail shop in Paris, France. Samples were selected from the same batch to ensure similar stage of ripeness. They were wrapped in a plastic film and maintained in a refrigerator until the test (stored for no more than one week).

Samples were cut with the aid of a sampler in a cylindrical shape $(\varnothing 8 \mathrm{~mm})$ with a length of about $10 \mathrm{~mm}$. As the shrinkage isotropicity during drying is an important information in this work, all samples were cut along well-identified product directions (Figure 2).

Sample was suspended on a specially designed support made with Molybdenum wire ( $0.25 \mathrm{~mm}$ of diameter) connected to the balance by a hook, with total length of ca. 60 $\mathrm{mm}$. Thanks to its very smooth surface, the friction coefficient of this wire is small enough to enable a quasi-free shrinkage of the sample.

\section{Experimental protocol}

Drying was carried out using the system described above. Apple and potato samples were submitted to four drying conditions, from the mildest to the more severe conditions: $30^{\circ} \mathrm{C}$ and $70 \% \mathrm{RH} ; 30^{\circ} \mathrm{C}$ and $40 \% \mathrm{RH} ; 50^{\circ} \mathrm{C}$ and $40 \% \mathrm{RH} ; 70^{\circ} \mathrm{C}$ and $40 \%$ RH. Experiments were conducted until quasi-equilibrium, which required 4 to 24 
hours, depending on the drying conditions. Duplicate runs were systematically performed. As duplicates were reproducible, only one typical result is presented for each product hereafter.

Mass, temperature and relative humidity were measured each $30 \mathrm{~s}$. Images were taking at each $300 \mathrm{~s}$, except for the fast tests at $70^{\circ} \mathrm{C}$ and $40 \% \mathrm{RH}$ for which images were taking each $120 \mathrm{~s}$. At the end of each experiment, the sample was put inside an oven (at $105^{\circ} \mathrm{C}$ ) for 24 hours to determine its dry mass. An example of raw data is presented in Figure 3.

\section{Data Analysis}

From the moisture content versus time curve, a drying rate curve was obtained by taking the slope of the mass reading at each time interval. The excellent quality of the mass measurement allows the derivative of the mass evolution to be computed with a low level of noise using a sliding window of only 5 experimental points.

The mass flux $\left(\mathrm{kg} / \mathrm{m} / \mathrm{s}^{2}\right)$, averaged over the entire exchange surface, is:

$$
q_{V}=\frac{d X}{d t} \frac{m_{s}}{A(t)}
$$

where $X$ is the moisture content (dry basis), $m_{S}$ is the oven-dry mass (kg) and $A$ is the exchange surface area $\left(\mathrm{m}^{2}\right)$.

The exchange surface area $A\left(\mathrm{~m}^{2}\right)$ was calculated from the height $h(\mathrm{~m})$ and diameter $d$ 
(m) of the image:

$$
A(t)=d\left(\frac{d(t)}{2}+h(t)\right)
$$

Equation (7) assumes that the cylinder maintains its cylindrical shape as drying progresses. This assumption is supported by experimental data for most part of the drying process (only the very late part of drying leads to deformed shapes) and by the values found for the off-diagonal term of the deformation tensor.

The volumetric shrinkage coefficient $\left(\beta_{\mathrm{V}}\right)$ was calculated from the following equation:

$$
v=\frac{V_{0} V_{t}}{V_{0}}
$$

where $V_{0}$ is the volume of the sample before drying and $V_{t}$ is the volume of the sample at time $t$. These volumes are computed with the diameter and height assuming a cylindrical shape.

Similarly, two directional shrinkage coefficients, longitudinal and radial, are defined:

$$
L(t)=\frac{L_{0} L_{t}}{L_{0}} \quad \text { and } \quad R(t)=\frac{R_{0} \quad R_{t}}{R_{0}}
$$

Where: $L_{0}$ and $R_{0}$ are the initial dimensions of the sample in longitudinal (here the diameter of sample) and radial (here the diameter of sample) directions, and. $L_{t}$ and $R_{t}$ the same variable at time $t$.

The shrinkage isotropicity is defined as the ratio of the longitudinal over radial 
shrinkage:

$$
\text { isotropicity }(t)=\frac{L^{(t)}}{R^{(t)}}
$$

\section{Identification of the characteristic drying curve}

The concept of characteristic drying curve was used to analyse the drying kinetics [19]. Consistently with previous works [6,7], the actual surface area of the sample is considered to analyse the drying rate. Therefore, the data are analysed in terms of drying rate flux (drying rate per surface area) rather than in the classical dying rate:

$$
q_{v}=\dot{X}_{0} \cdot f\left(X^{*}\right)
$$

Where $\dot{X}_{0}$ is the drying rate flux during the constant drying flux period, which lasts while the water activity at the exchange surface is equal to the unit and $X^{*}$ is the dimensionless moisture content:

$$
X^{*}=\frac{X \quad X_{c r}}{X_{c r} \quad X_{e q}}
$$

Where $X_{c r}$ and $X_{e q}$ are the critical (end of the constant drying flux period) and the equilibrium moisture content respectively.

Keeping in mind that the entire heat flux serves to liquid evaporation during the constant drying rate period, its value is classically expressed by the heat flux supplied to the sample per unit of surface area :

$$
\dot{X}_{0}=\frac{h\left(T_{d}-T_{w}\right)}{L_{v}}
$$

Where $h$ is the heat transfer coefficient, $T_{d}$ and $T_{w}$ the dry and wet bulb temperatures 
respectiveley and $L_{v}$ the latent heat of vaporisation at $T_{w}$.

In agreement with the smooth drying rate flux transition observed with our products at the critical moisture content, the mathematical expression selected for function $f$ is an order 3 polynomial which imposes a derivative equal to zero at the critical moisture content. Together with the two conditions included in the concept of characteristic drying curve $(f(0)=0$ and $f(1)=1)$, this polynomial is defined by one adjustable paramter :

$$
f(x)=x\left[\left(\begin{array}{ll}
1 & x
\end{array}\right)^{2}+x(3 \quad 2 x)\right]
$$

The best fit of this dimensionless curve is obtained by the indetification of 4 independant paramters $\left(\dot{X}_{0}, X_{c r}, X_{e q}\right.$ and $\left.\alpha\right)$. In order to avoid the noise due to the derivative of experimental data, equation (11) is integrated with the estimated paramters to obtain the theorical drying kinetics. The latter is then fitted to the experimental drying kinetics using a least squares estimator. This non-linear minimisation was performed using the Nelder-Mead method with a custom software.

Figure 4 shows the identification of the characteristic drying curve of potato dried at $70^{\circ} \mathrm{C}, 40 \% \mathrm{RH}$.

\section{RESULTS AND DISCUSSION}

\section{Drying rate flux during drying}

The knowledge of the mass flux during drying is a very important information of the 
drying process, since while liquid water is present at the exchange surface; the drying flux (mass loss per unit of time and area) is constant and depends only on the external conditions (temperature, relative humidity, velocity and flow configuration). Generally, this mass flux is calculated based on the initial surface of samples. The main advantage of our experimental device is the possibility to determine the actual exchange surface area of the sample during drying.

The drying rate flux, calculated according to the initial surface area and the actual reduced surface area is plotted versus moisture content (dry basis) in Figure 5 (drying at $\left.50^{\circ} \mathrm{C}, 40 \% \mathrm{RH}\right)$. The interest of accounting for the actual size of the sample becomes obvious in this figure. Thus, for potato (top) the mass flux based on actual surface area clearly depicts a period at constant mass flux, which proves the existence of a constant-rate stage, while such a period is completely hidden when using the initial surface area. The duration of this period was substantial, lasting up to a moisture content around $2.9 \mathrm{~kg}$ water/kg dry mass. For apple, no constant drying flux stage was observed for this drying condition $\left(50^{\circ} \mathrm{C}, 40 \% \mathrm{RH}\right)$, in spite of the exchange area correction. Apple presents a very different physical behavior compared to potato and this will be further explained by differences on anatomical structure between these products. Indeed, the absence of constant drying flux can be explained by the high porosity of apple. May and Perré [6] also observed this behavior on apple drying. This effect gave rise to an unsaturated porous medium that rendered capillary migration difficult. As the 
exchange surface was not saturated with free water, the second stage of drying (falling rate stage) started as soon as warm-up stage was over.

Several auteurs [1, 20-22] studied the convective drying of vegetable products (potato, carrot, tomato, grapes) and concluded in the absence of the constant-rate stage. But in all these works, the initial surface area was used to calculate the mass flux. May and Perre $[6,7]$ could use the actual surface area to calculate the mass flux. Even if they used a different system to acquire the shape of samples during drying (high-speed laser scan micrometers measuring the sample diameter and height at two fixed positions), they obtained same results as those here presented for potato and apple samples.

Figure 6 depicts mass flux based on actual surface area for potato (top) and apple (bottom) for four drying conditions. It can be observed that potato presents a constant drying flux stage for all drying conditions applied. For apple, this constant stage is only easily observed for the most severe condition $\left(70^{\circ} \mathrm{C}, 40 \% \mathrm{RH}\right)$. To the best of our knowledge, this is a new finding that was possible thanks to our unique device able to follow the sample mass and dimensions over a large range of drying conditions. The conjunction of two effects could explain this observation:

- the thermal activation of water transfer in the cellular structure (either by diffusion or liquid migration); 
- the temperature level that could be over the glass transition temperature of the wet cell walls, therefore allowing easy deformation of the cells with a reduction of porosity and increase of capillary action.

Table 1 presents the values identified for the characteristic drying curve for all drying conditions studied : mass flux at constant rate stage, critical moisture content and value or parameter . It can be observed that the mass flux at constant rate stage $\left(1^{\text {st }}\right.$ drying phase) is identical for both products (potato and apple) and it depends only on external conditions of drying, since both products have the same shape. For apple, the custom software allowed to identify a $1^{\text {st }}$ drying phase for mild drying conditions, but the critical moisture contents $\left(\mathrm{X}_{\mathrm{cr}}\right)$ were very high $\left(\mathrm{X}_{\mathrm{cr}}=3.45\right.$ for $30^{\circ} \mathrm{C}, 70 \% \mathrm{RH}$ and $\mathrm{X}_{\mathrm{cr}}=4.32$ for $\left.30^{\circ} \mathrm{C}, 40 \% \mathrm{RH}\right)$. Also, a constant drying flux stage was identified for the most severe condition $\left(70^{\circ} \mathrm{C}, 40 \% \mathrm{RH}\right)$. As earlier explained, this can be due to the conjunction of two effects: the thermal activation of water transfer in the cellular structure and the temperature level that could be over the glass transition temperature of the wet cell walls.

\section{Shrinkage}

Another important information that can be continuous obtained by this equipment is the shrinkage of the samples during the drying process. Figure 7 presents longitudinal shrinkage, radial shrinkage and anisotropy ratio versus moisture content for the 
experiments performed at $30^{\circ} \mathrm{C}, 70 \% \mathrm{RH}$. It must be highlighted that results obtained for other drying conditions presented the same shrinkage behavior. Apple (top) has an isotropicity close to the unit during all the drying process, which indicates an isotropic behavior. On the contrary, apple presented a higher radial shrinkage, compared to the longitudinal one. Its anisotropic behavior can be explained by the anatomical structure of apple, presenting oval shape parenchyma cells, aligned following the radial direction. Khan and Vincent [23] also observed the anatomical anisotropy of parenchyma cells of several apple varieties. Isotropiciy of potato can be explained by its hexagonal parenchyma cells. Figure 8 shows images of potato and apple saturated samples (before drying) obtained by environmental scanning electron microscope (ESEM, FEI Quanta 200). The anatomical structure of dried potato can also be observed in figure 8 (sample dried inside the ESEM chamber until 28\% RH), where the shrinkage of cell walls and the shape of parenchyma cells after drying can be easily distinguished.

\section{Volume loss vs moisture loss}

Finally, the respective variation of mass and volume during the process is an important information to better control the physical behavior, hence quality, of deformable products. To this intent, Figure 9 depicts the volume variation versus the volume of water removed. At our knowledge, no such curves were described in the literature for a wide range of drying conditions. Another advantage of these data is the continuous 
measurement during drying and the accuracy of measurements (typically $\pm 5 \mu \mathrm{m}$ and $\pm 0.02 \mathrm{mg}$ ). The different physical behaviors of potato and apple can be once again observed. Regardless the drying condition, potato lies right on a perfect bisector curve, depicting an ideal shrinkage behavior: the volume lost exactly matches the volume of liquid water removed. Only at the very end of the drying process, it can be observed that the curves do not follow anymore this bisector probably related to the casehardening effect. For apple, regardless of the drying conditions, and since the very beginning of drying, it can be observed that the volume reduction is higher that the volume of water removed from the samples. This fact can be explained by the high initial porosity of apples, which is of about $20 \%$ before drying [24]. This initial porosity was confirmed in our case by X-ray $\mu$-tomography observations (RX Solutions, resolution of $4.6 \mu \mathrm{m}$ ) (Figure 10). This figure presents a slice of a fresh Golden delicious apple's flesh, where dark gray voids can be observed between light gray parenchyma cells: the porosity estimated from this slice is of about $30 \%$. During drying, this porosity is likely to be reduced by the deformation of the cellular structure, which contributes to a higher reduction of the volume (compared to the loss of water). Again, we would like to emphasize that such very reproducible results can only be obtained because accurate shrinkage data can be acquired during the drying, without removing the sample from the dryer chamber. 


\section{CONCLUSIONS}

This paper present in detail a new experimental device devoted to continuous measurement of mass and dimension of highly deformable samples during convective drying. Potato and apple samples were submitted to several drying conditions. The mass flux based on actual surface of samples could be calculated and the first drying stage could be observed on potato samples. Clear differences in physical behavior of these two vegetable products were observed:

- a clear and long constant drying flux period for potato,

- absence of such a period for apple, except at $70^{\circ} \mathrm{C}$, probably due to the glass transition of the cell walls,

- isotropic shrinkage behavior for potato, anisotropic behavior for apple,

- ideal shrinkage for potato (volume loss = volume of removed water),

- non-ideal shrinkage for apple (the loss of volume is larger than the volume of water removed, due to a reduction of the initial porosity during cell collapse).

All these data are very reproducible and such curves are rarely observed for biological products. This was clearly possible thanks to our new device, which allows accurate measurements of mass loss and directional shrinkage values, without any perturbation of the drying conditions and over a large range of drying conditions (temperature and relative humidity). These data are prone to be used in the modeling of physical behavior during drying of highly deformable products. 


\section{ACKNOWLEDGEMENTS}

This research was supported by Capes Foundation (Brazil) and Erasmus mundus exchange program (European funds).

\section{REFERENCES}

1. Hawlader, M.N.A.; Uddin, M.S.; Ho, J.C.; Teng, A.B.W. Drying characteristics of tomatoes. Journal of Food Engineering, 1991,14, 259-268.

2. Ratti, C. Shrinkage during drying of foodstuffs. Journal of Food Engineering, 1994. 23(1), 91-105.

3. Wang, N.; Brennan, J.G. Changes in structure, density and porosity of potato during dehydration. Journal of Food Engineering, 1995, 24(1), 61-76.

4. McMinn, W.A.M.; Magee, T.R.A. Physical characteristics of dehydrated potatoes-Part I. Journal of Food Engineering, 1997, 33(1), 37-48.

5. Krokida M.K.; Maroulis Z.B. Effect of drying method on shrinkage and porosity, Drying Technology, 1997, 15:10, 2441-2458

6. May, B.K.; Perré, P. The importance of considering exchange surface area reduction to exhibit a constant drying flux period in foodstuffs. Journal of Food Engineering, 2002, (54), 271-282

7. Perré, P.; May, B.K. The existence of a first drying stage for potato proved by two independent methods. Journal of Food Engineering, 2007, (78) 1134-1140

8. Madiouli, J.; Sghaier, J.; Orteu, J. J.; Robert, L.; Lecomte, D.; Sammouda, H. Non-contact measurement of the shrinkage and calculation of porosity during the drying of banana. Drying Technology, 2011, 29(12), 1358-1364.

9. Groenewold, C.; Möser, C.; Groenewold, H.; Tsotsas, E. Determination of single-particle drying kinetics in an acoustic levitator. Chemical Engineering Journal, 2002, 86 (1-2): 217-222.

10. Schiffter, H.; Lee G. Single-Droplet evaporation kinetics and particle formation in an acoustic levitator. Part 1: Evaporation of water microdroplets assessed using boundary-layer and acoustic levitation theories. Journal of Pharmaceutical Science, 2007, 96(9): 2274-2283.

11. Perré, P.; May, B.K. A numerical drying model that accounts for the coupling between transfers and solid mechanics: Case of highly deformable products, 
Drying Technology Journal, 2001, 19: 1629-164.

12. Karunasena, H.C.P.; Senadeera, W.; Brown, R.J.; Gu, Y.T. A particle based model to simulate microscale morphological changes of plant tissues during drying. Soft Matter 2014, 10, 5249-5268.

13. Oevermann, M.; Gerber, S.; Behrendt, F. Euler-Lagrange/DEM simulation of wood gasification in a bubbling fluidized bed reactor. Particuology, 2009; 7(4), 307-316.

14. Perré, P. Experimental device for the accurate determination of wood-water relations on micro-samples, Holzforschung, 2007, 61: 419-429.

15. Dreisbach, F.; Losch, H. Magnetic suspension balance for simultaneous measurement of a sample and the density of the measuring fluid. Journal of Thermal Analysis and Calorimetry 2000, 62, 515-521.

16. Perré, P.; Houngan, A.C.; Jacquin, Ph. Mass diffusivity of beech determined in unsteady-state using a magnetic suspension balance, Drying technology, 2007, 25: $1341-1347$.

17. Perré, P.; Huber, F. Measurement of free shrinkage at the tissue level using an optical microscope with an immersion objective: results obtained for Douglas fir (Pseudotsuga menziesii) and spruce (Picea abies), Ann. For. Sci., 2007, 64: 255-265

18. Perré, P. MeshPore: a software able to apply image-based meshing techniques to anisotropic and heterogeneous porous media, Drying technology Journal, 2005, 23: 1993-2006.

19. van Meel, D.A. Adiabatic convection batch drying with recirculation of air. Chemical Engineering Science 1958, 9, 36-44.

20. Ghiaus, A.G.; Margaris, D.P.; Papanikas, D.G. Mathematical modelling of the convective drying of fruits and vegetables. Journal of Food Science, 1997, 62, $1154-1157$.

21. Sereno, A.M.; Medeiros, G.L. A simplified model for the prediction of drying rates for foods. Journal of Food Engineering, 1990,12, 1-11.

22. Zhao, Y.; Poulsen, K.P. Diffusion in potato drying. Journal of Food Engineering, 1988, 7, 249-262.

23. Khan, A.A.; Vincent, J.F.V. Anisotropy of Apple Parenchyma. J. Sci Food Agric 1990, (52), 455-466.

24. Joardder, M.U.; Kumar, C., Brown, R. J.; Karim, M.A. A micro-level 
investigation of the solid displacement method for porosity determination of dried food. Journal of Food Engineering, 2015, vol. 166, p. 156-164. 


\section{FIGURES AND TABLE}

Figure 1. A) Schematic diagram of the equipment set-up. B) Experimental setup: 1) Magnetic suspension balance; 2) Heating jacket enclosing the measuring chamber; 3) Sample's emplacement; 4) Balance control; 5) Moist air generator; 6) Camera and telecentric lens; 7) Lightning with a telecentric lens; 8) Illumination current regulator; 9) Chiller; 10) Temperature and relative humidity evaluation kit; 11) Gas supply for moist air generator; 12) Control and data acquisition.

Figure 2. Schematic draw of sampling showing the position, directions and size of potato and apple samples.

Figure 3. Example of raw data (apple: $30^{\circ} \mathrm{C}$ and $70 \% \mathrm{RH}$ ) and of images obtained at different drying times : 0, 350, 700 and 1400 minutes of drying.

Figure 4. Identification of the characteristic drying curve of potato dried at $70^{\circ} \mathrm{C}, 40 \%$ RH. Simulated curve of mass flux (continous line) in function of moisture content. $\mathbf{X}$ shows the critical moisture content (top). Experimental moisture content, simulated moisture content and absolute erreur of simulated moisture content in function of drying time (botom).

Figure 5. Variation of mass flux with moisture content for experiment realized at $50^{\circ} \mathrm{C}$ and $40 \%$ RH. Potato (top). Apple (botom). $\nabla$ Data analysis based on actual surface area. $\square$ Data analysis based on initial surface area.

Figure 6. Variation of mass flux (based on actual surface area) with moisture content at several drying conditions. Potato (top). Apple (botom).

Figure 7. Variation of shrinkage and isotropicity with moisture content for experiment realised at $30^{\circ} \mathrm{C}, 70 \% \mathrm{RH}$. Potato (top). Apple (botom). $\nabla$ Isotropicity. ORadial shrinkage. $\square$ Longitudinal shrinkage.

Figure 8. Anatomical structure of potato (saturated and dry conditions) and apple (saturated condition) obtained by ESEM (scale bar $=100 \mu \mathrm{m})$.

Figure 9. Volume loss versus moisture loss for several drying conditions. Potato (top). Apple (botom). The solid line (bisector) indicates the ideal case for which the volume change corresponds exactly to the volume of removed water.

Figure 10. X-ray micro-tomography 2D image of the Golden delicius apple's flesh. Light gray: parenchyma cells. Dark gray: voids.

Table 1. Measured physical properties of samples submitted to different drying conditions. 

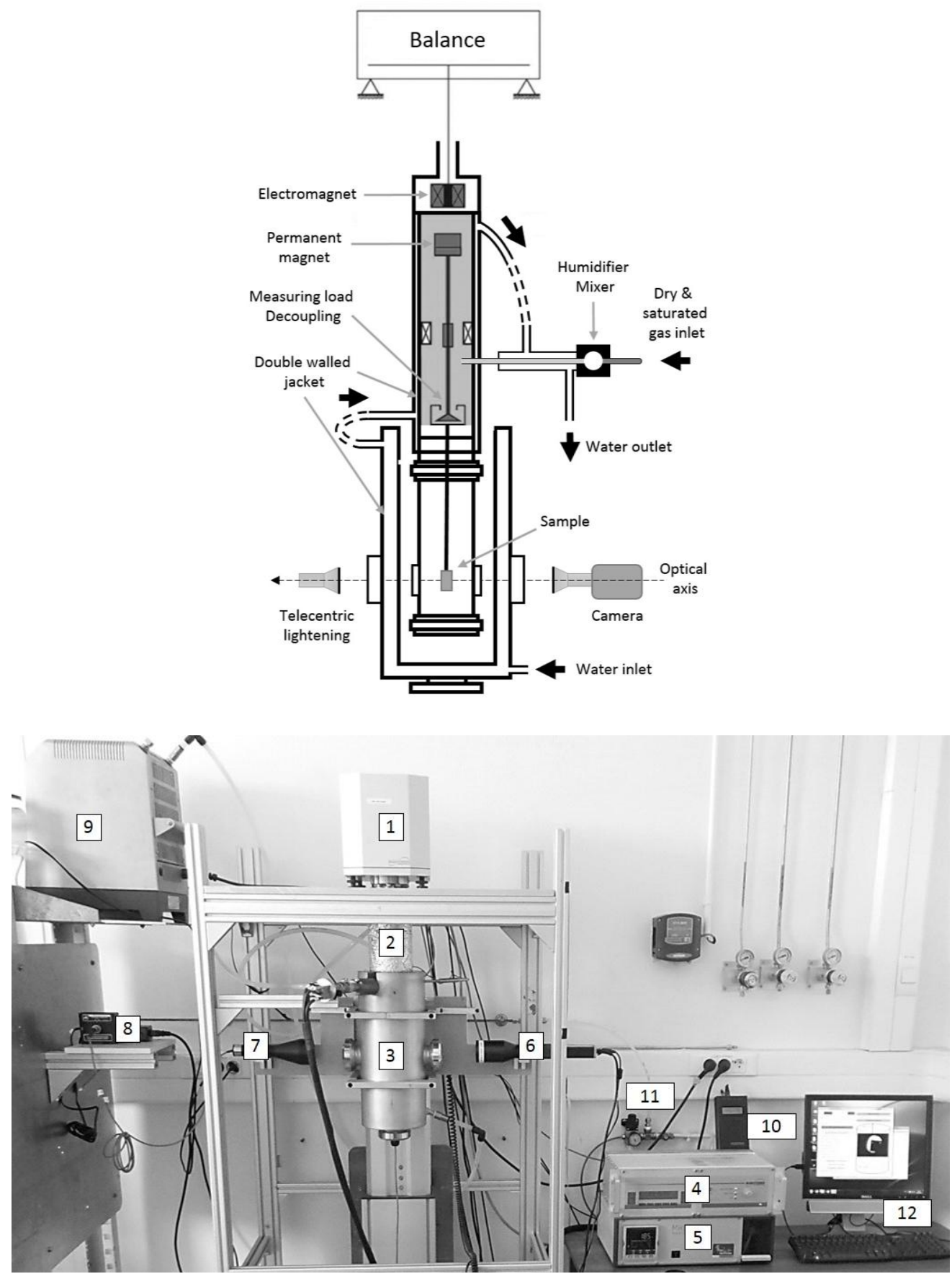

Fig 1. 


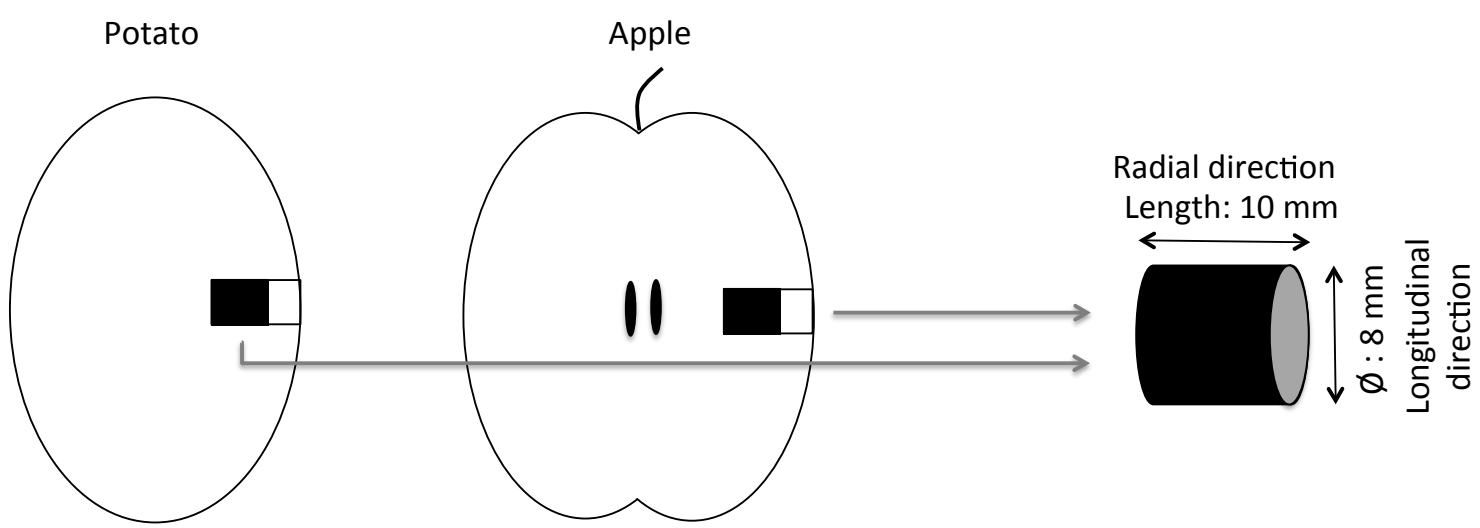

Fig. 2. 




Fig. 3 


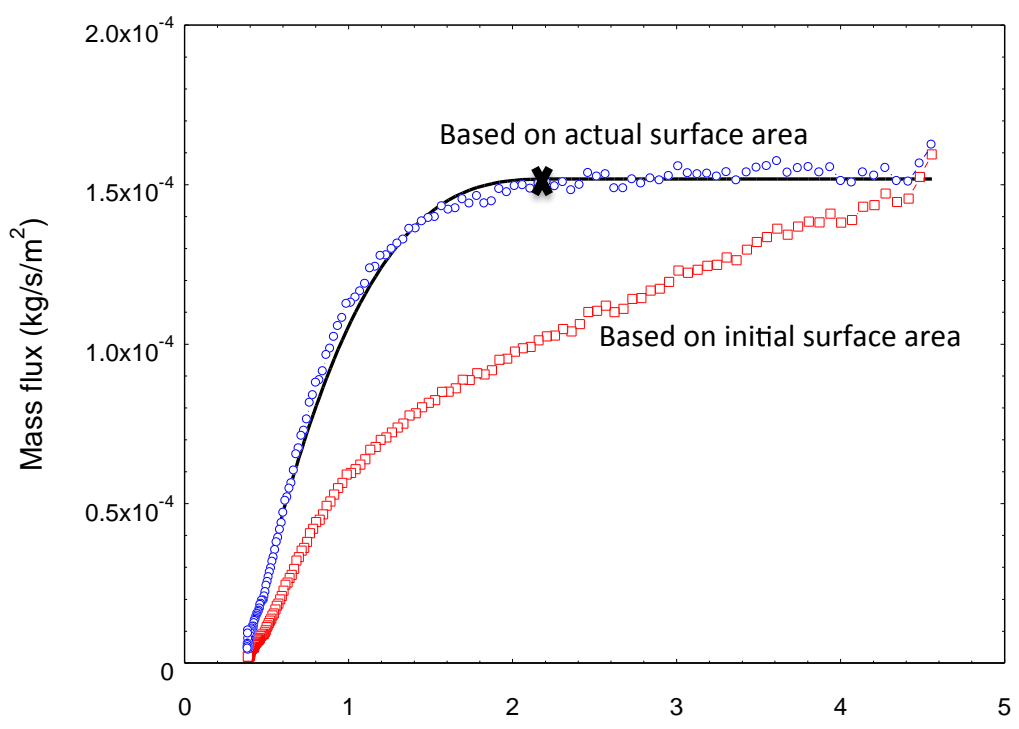

Moisture content (kg/kg dry mass)

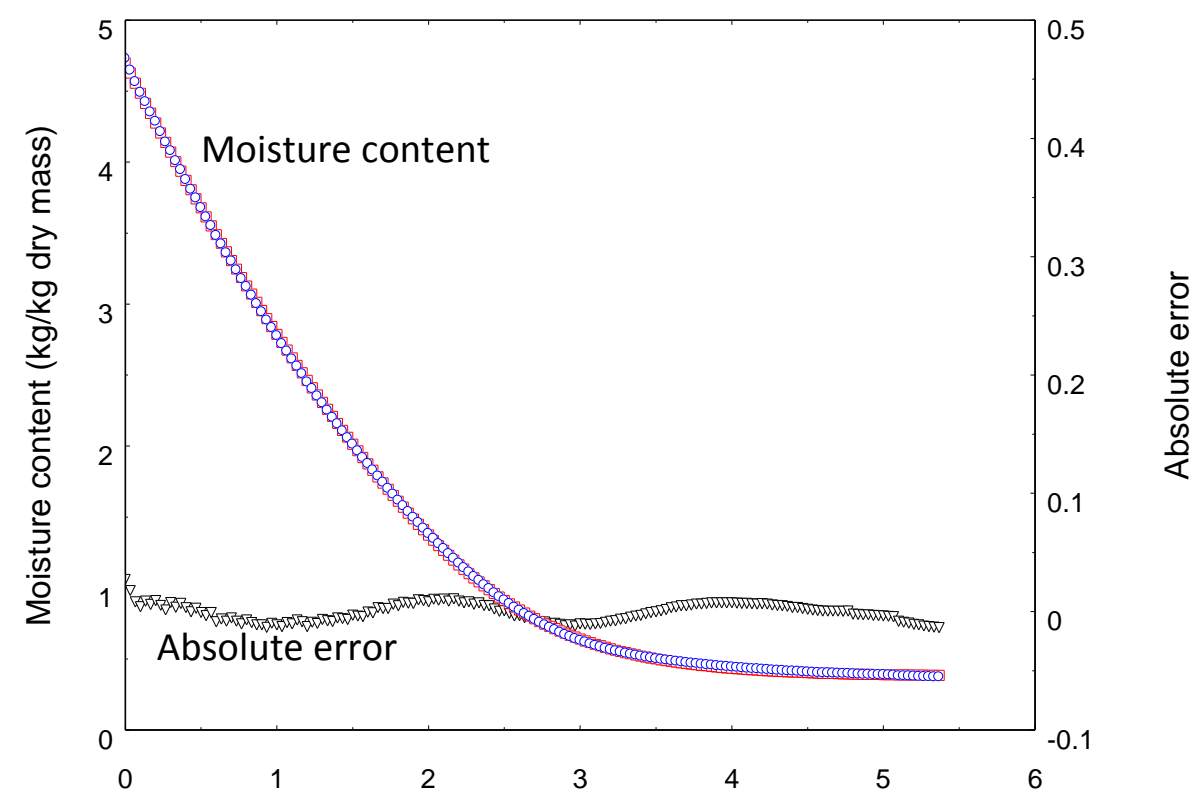

Drying time (h)

Fig. 4. 


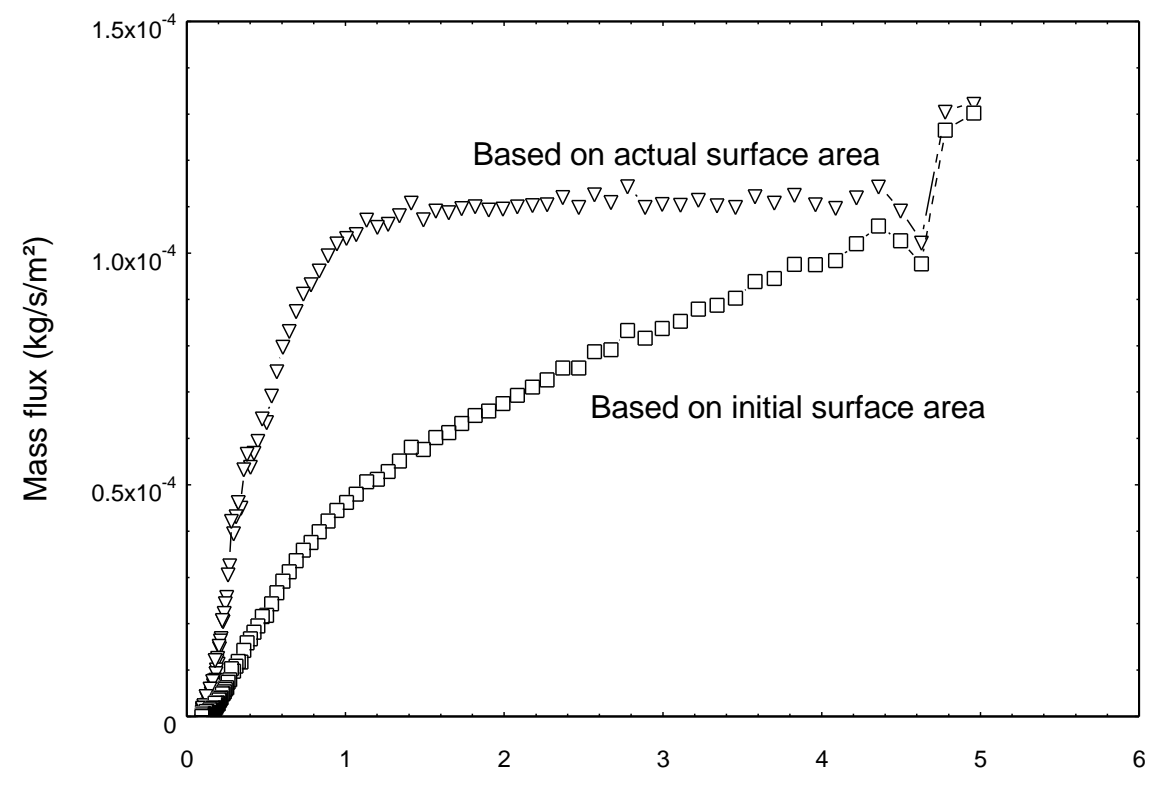

Moisture content (kg/kg dry mass)

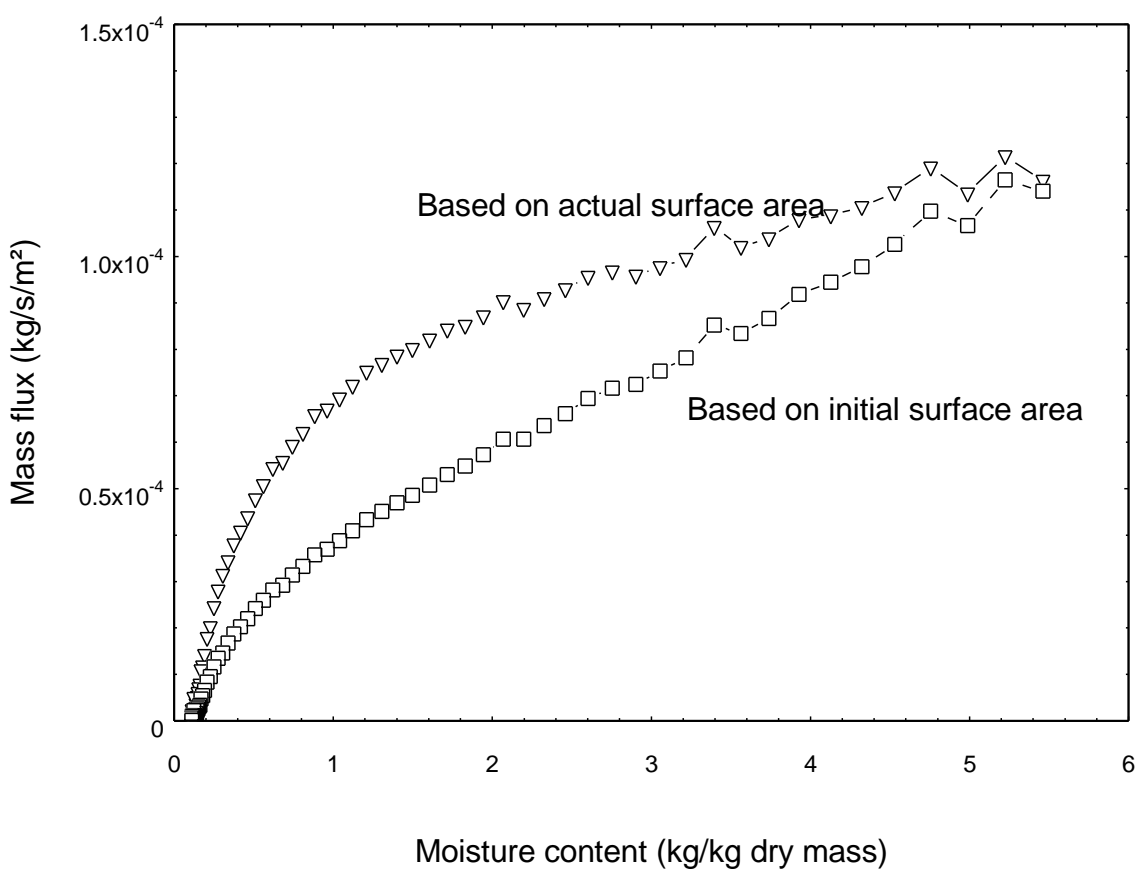

Fig. 5. 


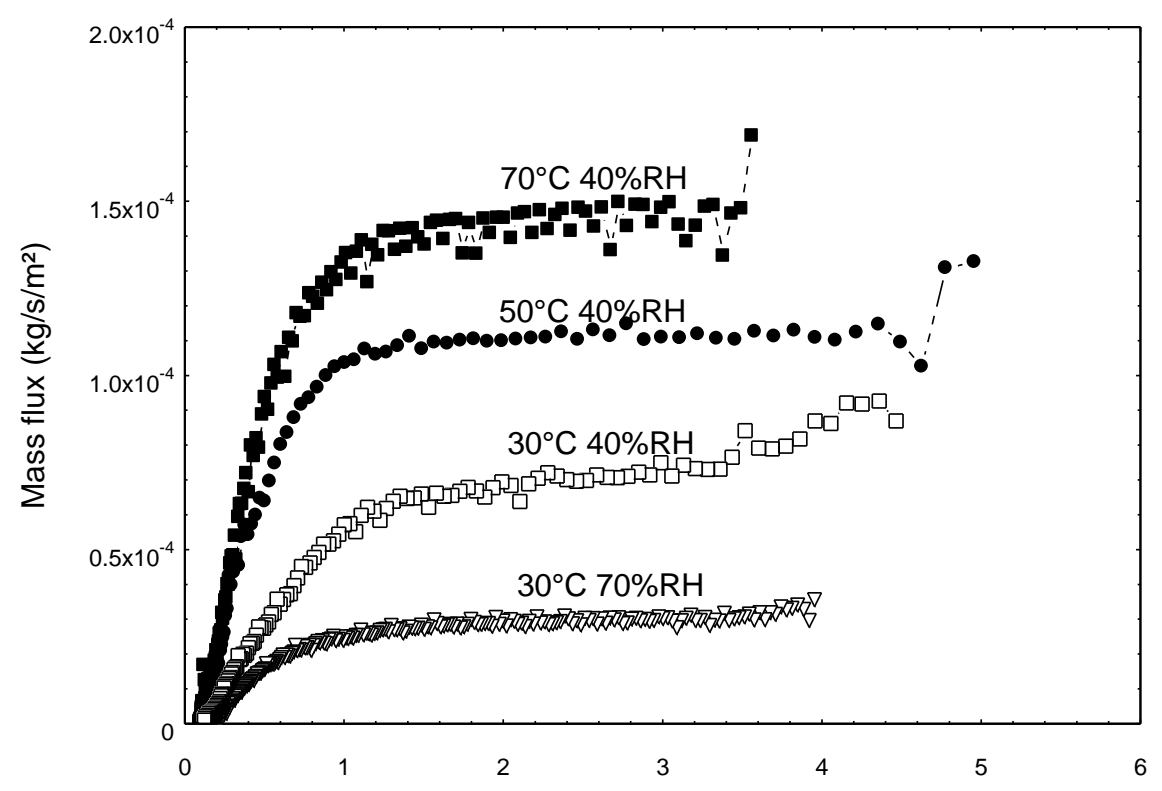

Moisture content (kg/kg dry mass)

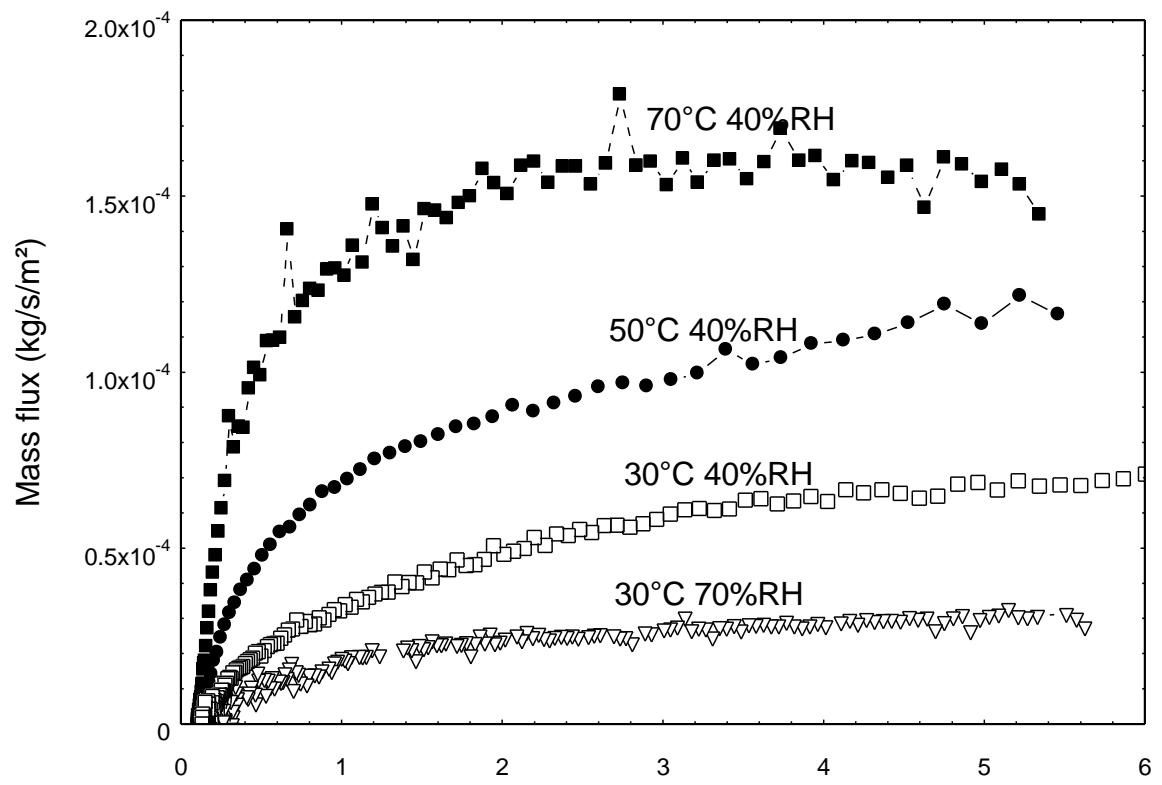

Moisture content (kg/kg dry mass)

Fig. 6. 


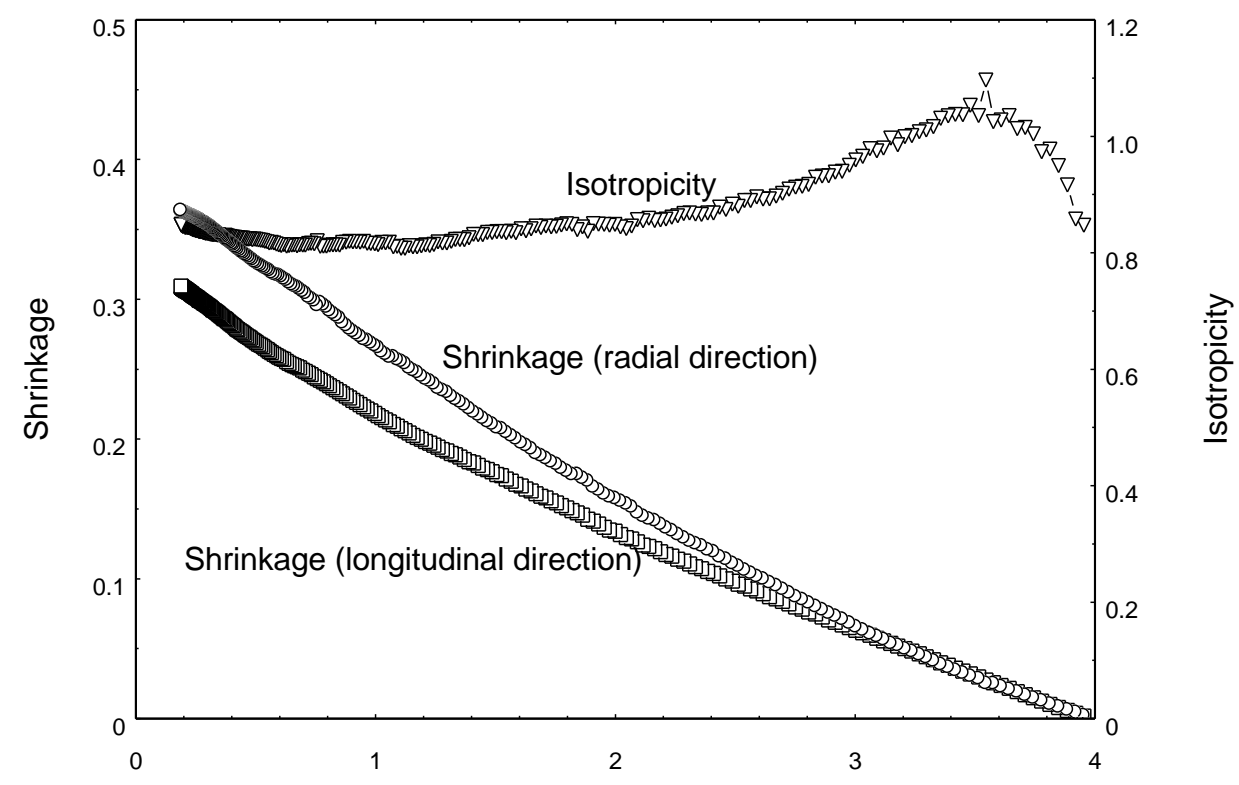

Moisture content (kg/kg dry mass)

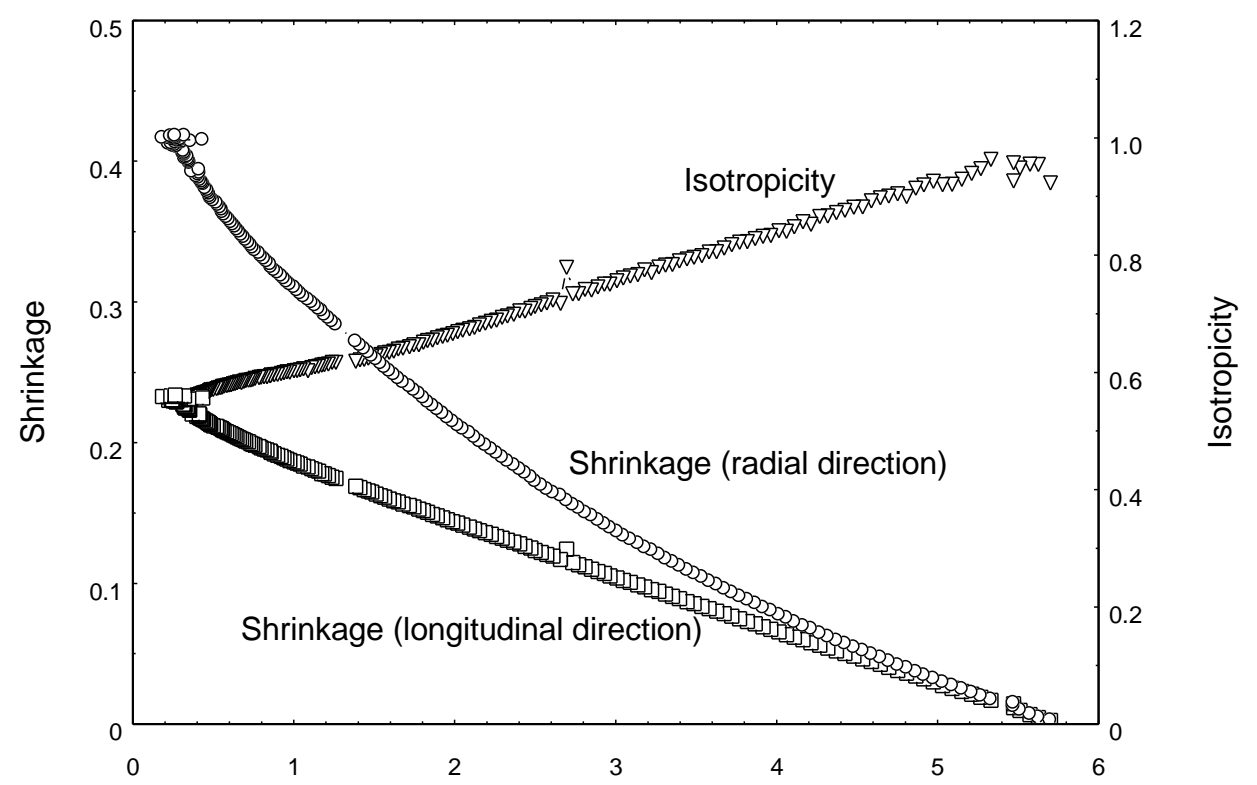

Moisture content (kg/kg dry mass)

Fig. 7. 


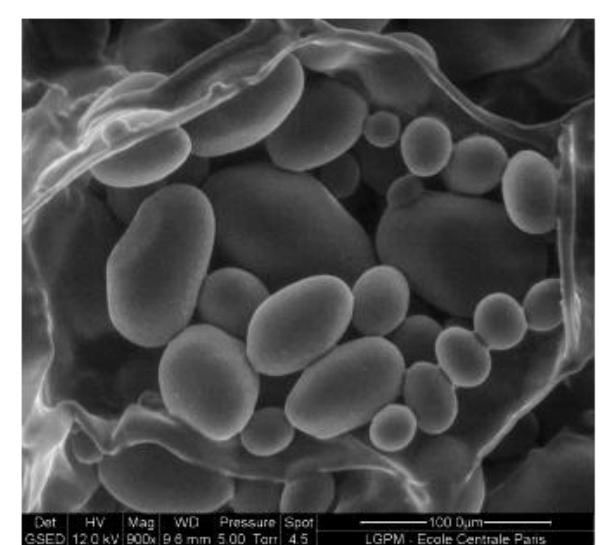

Potato_saturated condition

(665 Pa, $2^{\circ} \mathrm{C}, 95 \% \mathrm{RH}$ )

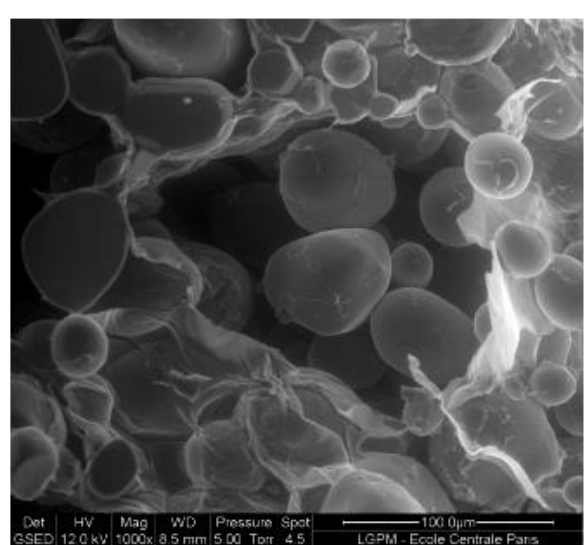

Potato_dried condition (665 Pa, 20 ${ }^{\circ} \mathrm{C}, 28 \% \mathrm{HR}$ )

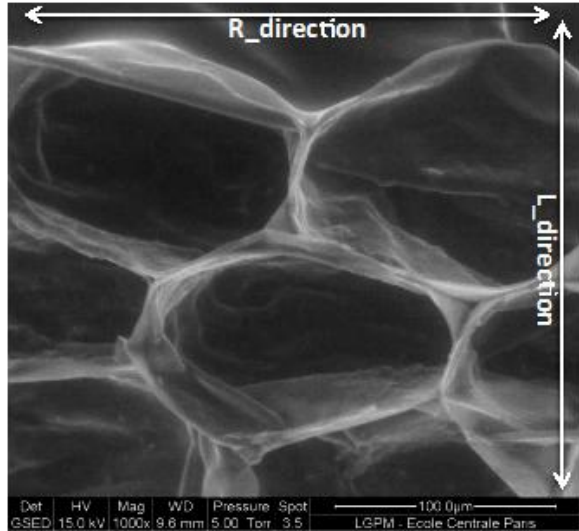

Apple_saturated condition (665 Pa, $2^{\circ} \mathrm{C}, 95 \% \mathrm{HR}$ )

Fig. 8. 

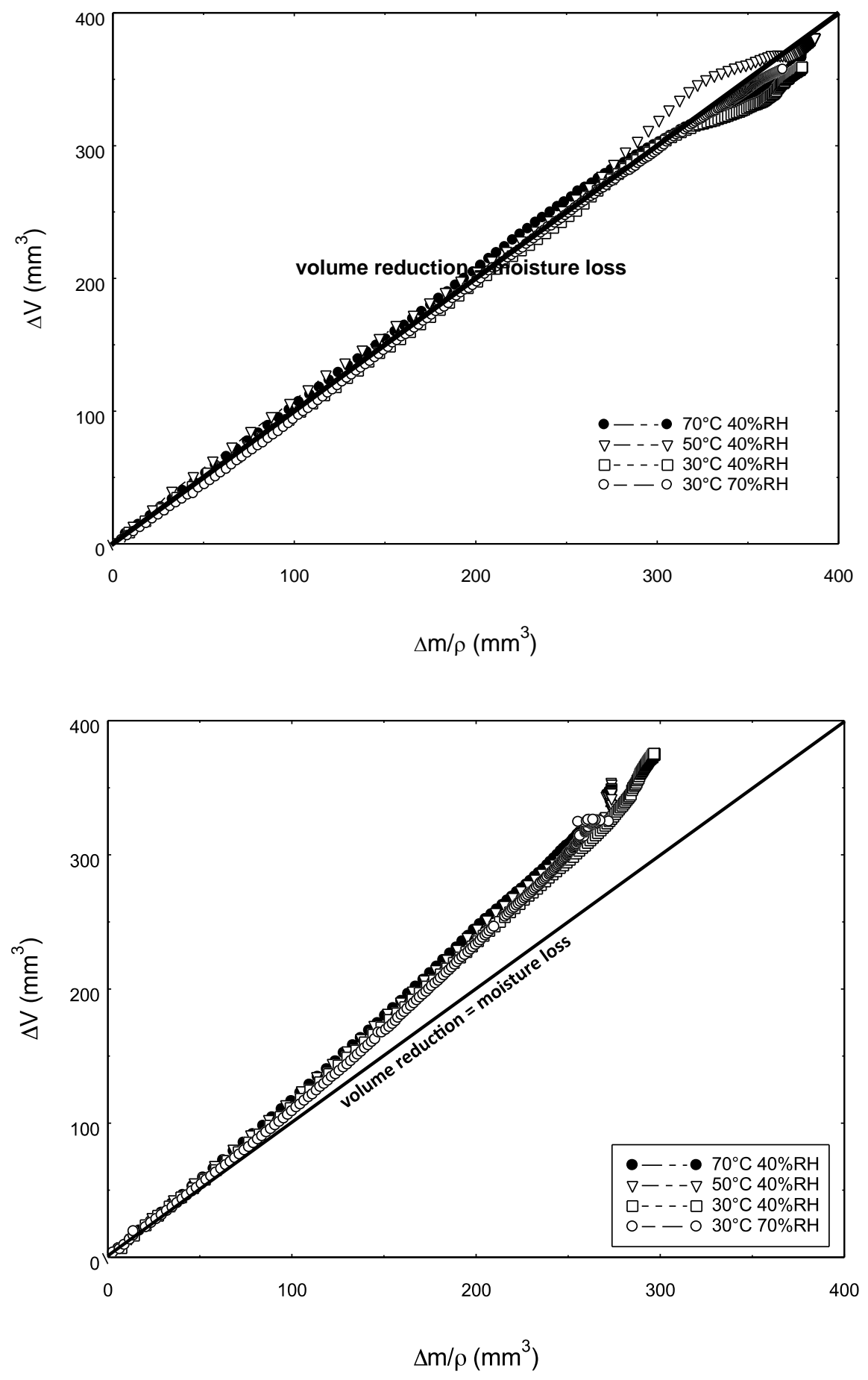

Fig. 9. 


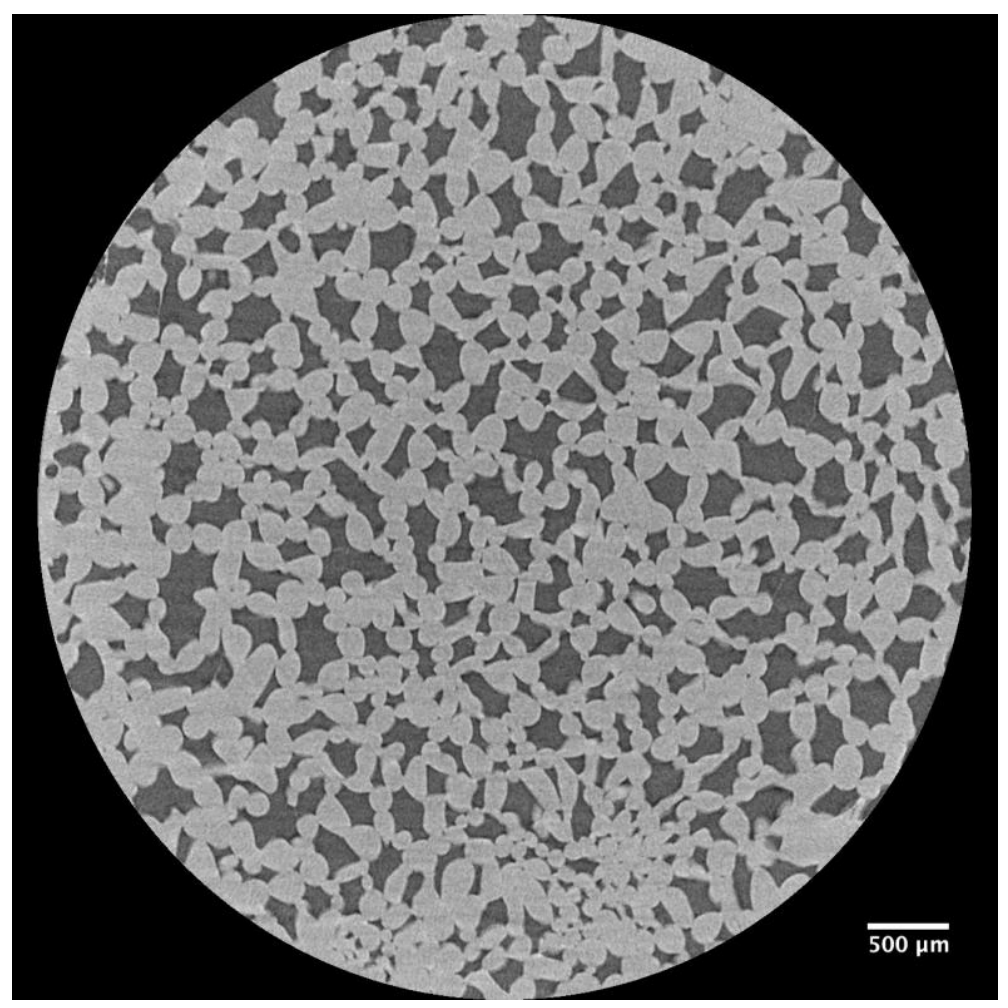

Fig. 10. 
Table 1.

\begin{tabular}{|c|c|c|c|c|c|c|c|}
\hline Drying conditions & L & $R$ & Isotropicity ${ }^{1}$ & $v$ & $\begin{array}{c}\dot{X}_{0} \\
\left(\mathrm{~kg} / \mathrm{s} / \mathrm{m}^{2}\right)\end{array}$ & & $\begin{array}{c}X_{c r} \\
\left(\mathrm{~kg} / \mathrm{kg}{ }_{\mathrm{db}}\right)\end{array}$ \\
\hline \multicolumn{8}{|l|}{ Potato } \\
\hline $30^{\circ} \mathrm{C}, 70 \% \mathrm{RH}$ & 0.37 & 0.21 & 0.6 & 0.69 & $2.88 .10^{-05}$ & 1.94 & 1.60 \\
\hline $30^{\circ} \mathrm{C}, 40 \% \mathrm{RH}$ & 0.41 & 0.20 & 0.5 & 0.72 & $7.32 .10^{-05}$ & 1.17 & 2.69 \\
\hline $50^{\circ} \mathrm{C}, 40 \% \mathrm{RH}$ & 0.35 & 0.17 & 0.5 & 0.65 & $1.03 .10^{-04}$ & 1.05 & 2.89 \\
\hline $70^{\circ} \mathrm{C}, 40 \% \mathrm{RH}$ & 0.38 & 0.20 & 0.5 & 0.69 & $1.52 .10^{-04}$ & 1.58 & 2.28 \\
\hline \multicolumn{8}{|l|}{ Apple } \\
\hline $30^{\circ} \mathrm{C}, 70 \% \mathrm{RH}$ & 0.33 & 0.27 & 0.8 & 0.67 & $2.78 .10^{-05}$ & 0.90 & 3.45 \\
\hline $30^{\circ} \mathrm{C}, 40 \% \mathrm{RH}$ & 0.34 & 0.27 & 0.8 & 0.68 & $6.23 .10^{-05}$ & 0.71 & 4.32 \\
\hline $50^{\circ} \mathrm{C}, 40 \% \mathrm{RH}$ & 0.36 & 0.32 & 0.9 & 0.73 & $\mathrm{n} / \mathrm{a}$ & $\mathrm{n} / \mathrm{a}$ & $\mathrm{n} / \mathrm{a}$ \\
\hline $70^{\circ} \mathrm{C}, 40 \% \mathrm{RH}$ & 0.28 & 0.30 & 1.1 & 0.63 & $1.54 .10^{-04}$ & 1.87 & 1.70 \\
\hline
\end{tabular}

$L, R_{R}$ and ${ }_{v}$ are the longitudinal, radial and volumetric shrinkage coefficients, respectively (coefficients determined at $0.5 \mathrm{~kg} / \mathrm{kg}$ dry basis).

$\dot{X}_{0}$ is the drying rate flux at constant rate stage.

$X_{c r}$ is the moisture content (dry basis) at the end of constant rate stage.

is the parameter for the shape of the characteristic drying curve $f$.

${ }^{1}$ measured at $0.5 \mathrm{~kg} / \mathrm{kg}$ dry basis.

$\mathrm{n} / \mathrm{a}$ : absence of constant rate stage. 